\title{
Erratum to: Urinary angiotensin converting enzyme 2 is strongly related to urinary nephrin in type 2 diabetes patients
}

\author{
Mariana Ciorba Pop ${ }^{1} \cdot$ Alina Ramona Potra ${ }^{1} \cdot$ Cosmina Ioana Bondor $^{2} \cdot$ \\ Diana Moldovan $^{1}$ - Crina Claudia Rusu ${ }^{1}$ - Dan Stefan Vladutiu ${ }^{1}$ - Ina Maria Kacso ${ }^{1}$
}

Published online: 16 January 2017

(C) Springer Science+Business Media Dordrecht 2017

\section{Erratum to: Int Urol Nephrol (2016) 48:1491-1497 \\ DOI 10.1007/s11255-016-1334-8}

The given name and family name of all authors were incorrectly published in the original publication, being referred by their first name. The correct given name and family name should read as follows: Ciorba Pop M, Potra AR, Bondor CI, Moldovan D, Rusu CC, Vladutiu DS, Kacso IM.

The online version of the original article can be found under doi10.1007/s11255-016-1334-8.

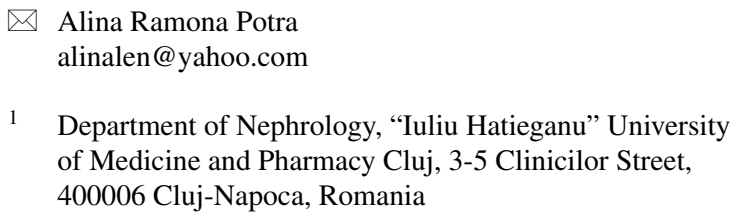

Alina Ramona Potra alinalen@yahoo.com

1 Department of Nephrology, "Iuliu Hatieganu" University of Medicine and Pharmacy Cluj, 3-5 Clinicilor Street, 400006 Cluj-Napoca, Romania

2 Department of Informatics and Biostatistics, "Iuliu Hatieganu" University of Medicine and Pharmacy Cluj, 6 Pasteur Street, 400349 Cluj-Napoca, Romania 